massive as the electron, with the occurrence of heavy nuclei in the rays at the top of the atmosphere, and with the Fermi theory of the origin of cosmic rays by the acceleration of particles in moving galactic magnetic fields. Of course, these discoveries have matured considerably in the intervening year. The book lays its emphasis on experimental methods and their immediate results, and this emphasis is strengthened by a copious and well-produced collection of photographs of apparatus and of cosmic-ray phenomena in cloud chambers and photographic emulsions. These photographs are admirable and make the book a pleasure to look through. But it is not clear who can use the book with advantageparts of it have a popular appeal, and indeed I suspect that some topics, like the use of manned stratospheric balloons, have earned their place by their spectacular rather than their scientific value.

However, the treatment is too detailed and its arrangement too confusing for the genoral reader. The physics student who thinks of entering cosmicray research will find his appetite whetted, but he will find it rather difficult to extract solid food. The difficulty arises partly from the rather capricious distribution of information among the chapters, and partly from the occasional omission of vital or helpful information. Certain figures, taken from original papers without their context, are unintelligible without prior knowledge; for example, the curves of cosmic-ray intensity at different altitudes and latitudes (p. 93) and the diagram of a complicated counter system (p. 168). The interpretation of several experiments, discussed at length in the book, turns on the way in which the ionization produced by a charged particle depends on its velocity, but this variation is only given in an algebraje form which is not easily apprehended and which is not specially emphasized. It is fair to adduce these points as evidence of hasty planning.

The translation is usually adequate, but it is rather laboured; and in a few places, including the title of Chapter 11, it descends to nonsense.

H. J. J. BRadDick

\section{PRESERVATION AND PROCESSING OF FRUIT}

Principles of Fruit Preservation

Jam Making, Canning and Drying. By T. N. Morris. (Monographs on Applied Chemistry, Vol. 6.) Third edition, revised. Pp. xiii +206 . (London: Chapman and Hall, Ltd., 1951.) 21s, net.

THE third edition of this excellent book will be welcomed by those wanting a summary of the current scientific views on fruit preservation. The principles underlying the formation of the pectin gel, the canning of fruit and can corrosion; and dehydration remain the chief subjects considered, while shorter chapters on refrigerating fruits, crystallizing, and fruit syrups and juices are also included. The references at the end of each chapter will be useful to those requiring further information on these subjects.

An introduction on the composition of fruits is very valuable, and the only criticism is that it could with advantage be enlarged to include such things as the proportion of stones present in the stone fruits, as well as more information on the eitrus fruits used in making marmalade.
The complex problem of the pectin -- sugar - acid gel is very clearly presented, and the text has been considerably revised in the second and third editions to include some of the more recent work on this subject. The chapter on fruit canning not only gives a general outline of the process, but also includes several tables on sugar strengths. The thermal-deathtime curves and rates of heat penetration well illustrate the necessity for using different processes for various products.

With so much useful information, it is disappointing to find that the tables for the minimum fruit contents in jams and in cans have not been revised for this edition, and there is no mention of the minimum density of syrup required for fruits canned in Great Britain. The ehapters on spoilage and the examination of eanned fruits both deal mainly with the problems of can corrosion, and this subject is covered excellently. Bacteriologists would, however, no doubt feel that their side of the examination of cans should be enlarged, especially when examining the less-acid fruits.

The chapters on dehydration are given in considerable detail, while those on cool storage and refrigeration, candied fruits, and fruit syrups and juices are less detailed, but sufficient to outline the main processes. One only wishes the author had included further sections on pickling, sauces and preservation by fermenting fruits. B. A. CraNG

\section{ANIMALS IN POSTAGE STAMPS}

\section{Zoology in Postage Stamps}

By W. Dennis Way and O.D. Standen. Pp. vii +113 +33 plates. (London: Harvey and Blythe, Ltd., 1951.) 18s. net.

THE collecting of postage stamps by subjects is

a hobby now widely practised, and already some dealers issue lists in which collections are arranged thematically. With this trend, it is not surprising to find biological subjects attracting many philatelists. Nor is it only dealers who are attempting to cater for their needs and to win others to their hobby. Museums have realized the value of thematic philately and have built up attractive displays to illustrate a particular subject. In New Zealand, for example, one enterprising museum has recently exhibited a collection of stamps to illustrate the natural history of that country.

Not unexpectedly, this existing and potential interest is now greeted by the appearance of an illustrated book showing the part played by animals in the design of postage stamps. The authors have not been unsuccessful in their endeavour and, besides introducing the philatelist to the animals in his collection, their book may well provide an opportunity for naturalists to gain a new hobby which will enrich and extend their own studies.

Since the purpose of the book is primarily philatelic, the animals, which are nearly all living and include one fossil and no mythological creatures, have been classified in an unusual manner. The more highly organized mammals are treated first; the least highly organized animals of which stamps have been made are described last. Within each group, however, the more primitive types precede the more advanced. Each group thus stands alone and only a general attempt has been made to link one with the 